\title{
Capsule Commentary on Kiechle et. al, Different Measures, Different Outcomes? A Systematic Review of Performance-Based versus Self-Reported Measures of Health Literacy and Numeracy
}

\author{
Derek Storch, BS and Jeffrey L. Jackson, MD MPH
}

Zablocki VAMC, Milwaukee, WI, USA.

J Gen Intern Med 30(10): 1537

DOI: $10.1007 / \mathrm{s} 11606-015-3325-3$

(c) Society of General Internal Medicine 2015

$\mathrm{T}$ he review by Kiechle et al. ${ }^{1}$ compared self-reported and performance-based measures of health literacy and numeracy in relation to several health outcomes. The authors asked a focused clinical question and conducted a reasonably broad search, though they limited themselves to MEDLINE and did not search other databases such as EMBASE, CINAHL, the Cochrane library, PsycINFO or ERIC. While the 2011 Agency for Healthcare Research and Quality (AHRQ) systematic review of literacy and numeracy found 87 articles, ${ }^{2}$ Kiechle et al. found only four studies directly comparing performance-based and self-reported measures of health literacy. They found no differences in outcomes between the two measures, though the data were quite sparse.

It would be useful to be able to measure health literacy and numeracy using self-reported rather than performance-based measures, as self-reporting is generally easier to administer - the instruments can be filled out by patients in the waiting room rather than requiring someone to administer them. What remains unclear is whether the underlying theoretical constructs are equivalent between performance-based and self-reported literacy measures. ${ }^{3}$ Performance-based measures may measure literacy more directly, while self-reports may be influenced by factors that affect patients' perceived ability (such as confidence and other social constructs). Whether this difference affects health outcomes is an impor-

Conflict of Interest: The authors have no conflicts of interest with regard to the material in this article.

Corresponding Author: Jeffrey L. Jackson, MD MPH; Zablocki VAMC, Milwaukee, WI 53295, USA (e-mail: jjackson@mcw.edu).

\section{REFERENCES}

1. Kiechle ES, Bailey SC, Hedlund LA, Viera AJ, Sheridan SL. Different Measures, Different Outcomes? A Systematic Review of Performance-based versus Self-reported Measures of Health Literacy and Numeracy. doi: 10.1007/s 11606-015-3288-4

2. Berkman ND, Sheridan SL, Donahue KE, Halpern DJ, Viera A, Crotty K, et al. Health literacy interventions and outcomes: an updated systematic review. Evidence Report/Technology Assessment. United States: Agency for Healthcare Research and Quality; 2011 Mar. Report No.: 199.

3. Jordan JE, Osborne RH, Buchbinder R. Critical appraisal of health literacy indices revealed variable underlying constructs, narrow content and psychometric weaknesses. J Clin Epidemiol. 2011;64(4):366-79.

This comment refers to the article available at: http://dx.doi.org/10.1007/ s11606-015-3288-4.

Published online July 30, 2015 